\title{
Modern Aspects of the Motivation of the Staff of a Commercial Enterprise Through the Social Menu System
}

\author{
Evelina P. Pecherskaya ${ }^{1 *}$, Tatiana M. Tarasova ${ }^{1}$ \\ ${ }^{1}$ Samara State University of Economics, Soviet Army Str., 141, 443090 Samara, Russia
}

\begin{abstract}
At present, a very difficult situation is developing in the economy, which should be characterized as "personnel shortage". Every year this situation is complicated by the deteriorating demographic situation. Moreover, at present, in most companies, the incentive process is imperfect, since in most cases it does not depend on the results of the employee's work.

Well-thought-out stimulation helps to best manage the business behavior of staff, ensuring the welfare of the organization. Most domestic enterprises strive to create conditions to meet the needs of their employees and are very successful in this. Therefore, a high wage level and the offer of a full social package, training and career planning for employees, organizing corporate events, diagnosing the situation in a company with the involvement of external consultants and conducting surveys among staff gradually become familiar working conditions for employees of commercial organizations.

The article conducts a study of the incentive system for the labor activity of the "Fix Price" sales department, which was carried out on the basis of an analysis of the company's internal regulatory documents and by questioning the employees. This study revealed the main problems in the functioning of the current system of motivation, on the basis of which measures were proposed to improve the personnel incentive system and a model of external motivation of staff was proposed.
\end{abstract}

Keywords: staff motivation, staff incentive system, social package, staff hunger, wages.

\section{Introduction}

The relevance of the research lies in the fact that in a market economy, professional skills and personal qualities of employees help organizations gain an advantage over competitors [1]. Employees provide an enterprise profit, which can be significantly increased by paying sufficient attention to staff development, building loyalty to the organization in it, creating an atmosphere within the team suitable for successful work. Thus, staff incentives are the foundation for ensuring efficient use of resources [2].

\footnotetext{
*Corresponding author: pecherskaya@,sseu.ru
} 
Stimulation is the indicator that is able to objectively demonstrate the initiative of staff, the development of its potential. If employees have not enough incentives to work better, more efficiently, there is no clear focus on the results of the activity of the whole enterprise and each individual employee, then there will be no interest in work and the desire to work for the benefit of the company's owners under any circumstances [3].

Difficulties in the development and implementation of effective staff incentives are associated with constantly changing market conditions that have a significant impact on the company and its individual employees [4].

\section{Problem Statement}

At present, a very difficult situation is developing in the economy, which should be characterized as a "personnel shortage". There is an acute shortage of highly qualified specialists in most industries. Every year this situation is complicated by the deteriorating demographic situation. Moreover, at present, in most companies, the incentive process is imperfect, since in most cases it does not depend on the results of the employee's work [5]. Often, employees are paid a fixed salary; bonuses are issued on significant dates (excluding the employee's contribution to the work of the enterprise). In these criteria, a well-designed incentive process is the main element of the personnel management system, especially for fast-growing and dynamically developing companies [6].

\section{Research Questions}

Competently thought-out incentives help to best guide the business behavior of staff, ensuring the welfare of the organization. Most domestic enterprises strive to create conditions to meet the needs of their employees and are very successful in this. Therefore, a high wage level and the offer of a full social package, training and career planning for employees, organizing corporate events, diagnosing the situation in the company with the involvement of external consultants and conducting surveys among staff gradually become familiar working conditions for employees of commercial organizations [7].

The purpose of the research is to study the system of personnel incentives in the enterprise, conduct analysis and develop recommendations for its improvement.

The function of motivation is that it influences the labor collective of an enterprise in the form of incentives for effective work, social influence, collective individual incentive measures. These forms of influence intensify the work of the subjects of management; increase the efficiency of the entire system of management of an enterprise and organization.

\section{Methods}

The analysis of the incentive system for the organization's personnel will use the example of the Best Price LLC limited liability company, the FixPrice department of the city district of Chapayevsk.

The FixPrice chain of stores operates in the "fixed price store" format, also known as variety store, pound shop, dollar store and is a universal retail store selling a wide range of both food and non-food items at the same price.

Consumers of a store are citizens aged from 7 years to 70 years, with different levels of up-coming. On average, the FixPrice store serves up to 1,000 thousand consumers per day. 
Traditionally it is believed that the main potential of any company is in personnel, since no organization can achieve its goals and survive in the competition without the skilled workers it needs.

Figure 1 shows the personnel management system, LLC "Best Price". As can be seen from the figure, the personnel management system consists of the following elements: personnel selection, personnel assessment, personnel placement, personnel adaptation, personnel training.

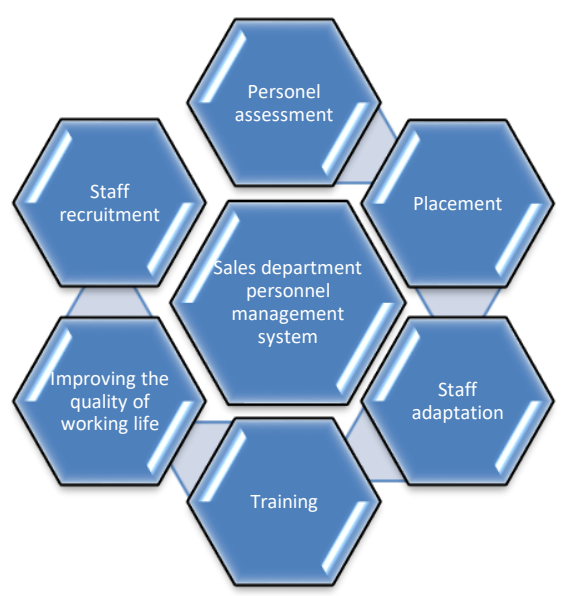

Fig. 1. Personnel management system of Best Price LLC

Source: Authors.

The study of the incentive system for the labor activity of the "FixPrice" sales department was carried out in two ways.

Personnel incentives were studied on the basis of an analysis of the company's internal regulatory documents: orders and directives of the general director, internal labor regulations of employees of the sales department, job descriptions and other local instructions. Analyzing the documents of the enterprise, attention was drawn to the following factors: wages; material benefits; intangible benefits; negative incentives (punishments); staff turnover.

The second way to study the incentive system for employees of the sales department "FixPrice", used in the work, is the questionnaire survey of employees using a specially designed questionnaire. The questionnaire included 29 questions. With the help of this questionnaire 20 people were interviewed, employees of the sales department. The questionnaire was anonymous and was not conducted in the presence of management. When drafting the questionnaire, it was taken into account that there is a set of external conditions in the context of work: remuneration (salary); job security; working conditions; status; the quality of leadership and intra-company relations between colleagues, with superiors, subordinates. The presence of these conditions, satisfying the individual, does not necessarily stimulate his work activity. However, their absence affects the satisfaction of employees, as they need, at least, to maintain a level that can be called a lack of dissatisfaction. Therefore, the external conditions in this theory are called dissatisfaction factors, or hygienic factors.

When selecting the questionnaire questions, it was also taken into account that there is a system of internal conditions related to the very content of the labor process: achievement; confession; a responsibility; advancement; proper work; growth opportunity. The absence of these conditions is not an indication of a large degree of dissatisfaction. However, if they 
are present in the labor process, they give it strong motivational incentives, resulting in a good job performance.

Next, we present a qualitative and quantitative analysis of the results obtained on the motivation system in the sales department of FixPrice.

Questioning of employees of the sales department «FixPrice». To the question "Is your work interesting for you?" $60 \%$ of employees answered: "Yes", $10 \%$ of employees answered: "Rather yes", $30 \%$ of employees of the sales department answered "Rather no". Among the frequent reasons for the lack of interest in the work were the following: "tired", "boring, everything has been known for a long time", "I do not expect anything good". Other employees are interested in work, because "communicate with interesting people", "constantly learn something new", "up-to-date on new products of consumer equipment". In our opinion, there is a negative trend of loss of interest in the work of employees of the sales department.

Answering the question "Do you perceive your work as something important, valuable and worthwhile?" The answers were divided as follows. "Yes" answered 45\% of employees in the sales department. "More likely yes" was chosen by $25 \%$ of workers. "Rather not," responded $25 \%$ of workers. One worker does not know how to perceive his work as something important and valuable or worthless, useless. Not a single worker perceives their work as something worthless and useless. Most workers consider their work effective and advisory. These are $65 \%$ of employees. "Rather not," said $35 \%$ of the workers.

$70 \%$ of workers believe that work consists of several frequently repeated operations, it is monotonous. And only $30 \%$ of workers were able to say that work consists of many rarely repeated operations, it is diverse; you can independently plan the work and determine its mode. It turns out that monotony is a factor that can cause (already causes) a growth of dissatisfaction among workers.

To the question "Do you often have to work under conditions of increased workload, with overwork, with over fulfilment of the norms?" Workers answered as follows: "often" $-40 \%$, "sometimes" $-45 \%$, "seldom" $-10 \%$, never "- $5 \%$. It can be concluded that the work of staff is stressful.

$45 \%$ of respondents answered that they are satisfied with the work schedule and $55 \%$ of respondents answered that they are dissatisfied with their work schedule. In order to increase job satisfaction, a change in work schedule is necessary.

$25 \%$ of workers believe that their working conditions are comfortable, the rest of the respondents answered "no" and "rather no" (75\% of employees). A sufficiently large percentage of workers are dissatisfied with working conditions.

Most workers do not see the connection between the results of their work and their salaries. And this is despite the fact that in the sales department there is a bonus for over fulfilling the sales norms. According to the theory of expectation, the worker should have a stable idea that the results of his work depend on his efforts, that certain results for him result from his work, and also that the results he obtained ultimately have value for him. This is not happening in FixPrice LLC. In the absence of these conditions, or even one of them, the incentive process will be extremely complex or even unworkable.

We list the most important labor incentives for the employees of the "FixPrice" sales department (in descending order): remuneration, working conditions, relations with management, promotion, relationships with colleagues, professional development and selfactualization, satisfaction with the work done.

Employees of a commercial enterprise were asked to list other methods of additional incentives used in this enterprise, but no one took advantage of this opportunity.

Most of the employees of the FixPrice sales department noted that they were completely unhappy with the amount of wages $-65 \%$. The other part of the workers $(25 \%)$ wage "doesn't satisfy". And only $10 \%$ of employees chose the answer "rather satisfied". There 
were no workers, who were completely satisfied with the amount of wages, at this trade enterprise.

To the question "Are employees always given objective and deserved thanks?" The employees answered as follows: yes, rather $-40 \%$, I don't know $-20 \%$, probably not $25 \%$, no $-15 \%$. Considering an unfair or unequal assessment of his work, a person loses the motivation for active creative, from the point of view of the organization, actions that can lead to many negative consequences.

$20 \%$ of the employees of a commercial enterprise believe that the management quite objectively evaluates the results of their work. $20 \%$ of workers argue that the assessment of their work is more objective than subjective. $15 \%$ of employees have not yet understood the essence of the assessment of their work by management and responded to the question: "I do not know." $35 \%$ of workers are confident that the assessment of their work is more biased than objective. $10 \%$ of workers noted that the assessment of their work is completely biased. There is a rather negative trend. According to the theory of equality, one of the constant aspirations of people is the desire to receive a fair assessment of their actions. If justice is violated, if individual members of the organization receive an undeservedly high rating and reward, then the person feels offended, and this leads to frustration and dissatisfaction. Considering an unfair and unequal assessment of his work, a person loses his motivation for active creative, in terms of the goals of the organization, actions, which leads to many negative consequences. For example, a person may decide for himself that it is necessary to reduce costs, that he does not need to work much, to expend great efforts; criminal attempts to compensate for underpayment are possible, a person can leave the organization, etc.

$75 \%$ of employees said that the management feel maximum supervision, control over their work. $25 \%$ of employees expressed their opinion on the average level of supervision and control over their work by management. And $0 \%$ of employees oversight, management control identified as minimal.

To the question "The results of your work depend on the degree of your efforts?" Half of the workers answered that rather yes $-50 \%$ of employees. The remaining half of the workers are confident that the results of their work do not depend on the degree of their efforts.

To the question "Is the staff" punished with a ruble "fairly, depriving bonuses, making cash deductions from wages, fines, collecting shortages, etc.?" The following answers were received: $5 \%$ of employees answered: "I completely agree", $10 \%$ workers - "rather agree", $15 \%$ - "I do not know", $60 \%$ - "rather disagree", $10 \%$ - "completely disagree". It turns out that $70 \%$ of workers do not agree with the fairness of material penalties.

The opinions listed above allow us to conclude that the majority of workers are not convinced either of fair remuneration or fair disciplinary action, which does not best affect their motivation.

\section{Findings}

An analysis of internal documents made it possible to draw the following conclusions about the incentive system for employees of the sales department of FixPrice.

In the Best Price LLC in order to improve the staff incentive system, the following activities were proposed and carried out:

Stage 1. At the first stage - determination of tariff rates for various categories of personnel, pre-payments and allowances, determination of the procedure for calculating and the size of collective bonuses and payments from profits.

Stage 2. At the second stage, a collective agreement was concluded between the administration of the company and employees. 
The collective agreement enshrines: the size of the minimum tariff rate; tariff coefficients for all categories of employees; the procedure for compensation of wages in terms of inflation; forms of participation of employees in the incomes of the enterprise (collective bonuses, payments from profit); forms and sizes of social benefits and the procedure for their provision.

Stage 3. It was proposed to expand the functional responsibilities of the director:

It was proposed to include in the duties of the deputy director of the sales department the following functions: participation in the development of incentives; overall management of the employee incentive process; motivational management of managers; participation in the development and implementation of working standards (service standards, standards of relationships in a team); collection and processing of information about the results of shifts.

The company's accountant, in our opinion, should act as a functional unit or technical support unit for the personnel incentive process. The functions of the accountant of the companionable company "FixPrice" we proposed to include the following:

- participation in the development of a system of incentives for labor activity of personnel;

- planning costs associated with staff incentives;

- implementation of material remuneration of employees;

- collection and analysis of information on financial performance enterprises, its services, individual employees;

- determining the effectiveness of the incentive effect on employees' work activity.

Stage 4. Changing the wage system. It was proposed to change the wage system in the department of FixPrice. For line personnel (except for the category of workers), it took the following form (Figure 2).

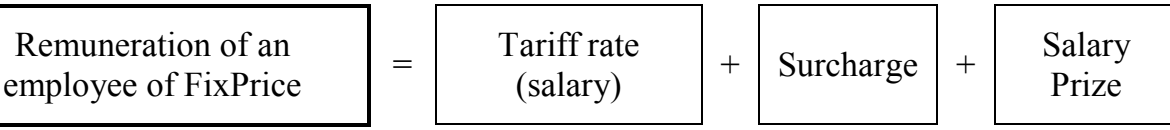

Fig. 2. The changed wage structure of workers of the companionable company "FixPrice"

Source: Authors.

The employee is actually paid time on the basis of the tariff rate.

Allowance - a stimulating payment to the tariff part, bearing a permanent or temporary character for irregular working hours, work experience, for high professional skills, high achievements in work, for intensity and intensity of work, for doing particularly important work, etc. Table 1 presents the sizes of the proposed surcharges for line staff.

Table 1. The size of the proposed allowances to the tariff salary of employees of the "FixPrice"

\begin{tabular}{|l|l|l|}
\hline \multicolumn{1}{|c|}{$\begin{array}{c}\text { Offered } \\
\text { surcharges }\end{array}$} & Size of surcharge & \multicolumn{1}{c|}{ Condition of payment of surcharge } \\
\hline \multirow{2}{*}{$\begin{array}{l}\text { 1. Premium for } \\
\text { work experience }\end{array}$} & $10 \%$ of the salary & 2 years of uninterrupted work experience inthe "FixPrice" \\
\cline { 2 - 3 } & $20 \%$ of the salary & 3 years of uninterrupted work experience inthe "FixPrice" \\
\cline { 2 - 3 } & $30 \%$ of the salary & 4 years of uninterrupted work experience inthe "FixPrice" \\
\cline { 2 - 3 } $\begin{array}{l}\text { 2. Surcharge for } \\
\text { the level of } \\
\text { education }\end{array}$ & $20 \%$ of the salary & 5 years of uninterrupted work experience inthe "FixPrice" \\
\cline { 2 - 3 } & $10 \%$ of the salary & $\begin{array}{l}\text { The presence of higher professional education, confirmed by assigning } \\
\text { the person who successfully passed the final certification, qualification } \\
\text { "Master" or "Chartered Specialist" in the financial and economic field } \\
\text { financial and economic field is not less than 3 courses }\end{array}$ \\
\hline
\end{tabular}

Source: Authors. 
In FixPrice for line personnel (except for workers), this rate of reward is used as the growth in sales. Bonus conditions - the excess of the base sales of the month. The figure of 600 thousand rubles was taken as the base sales volume of the month. When this number was exceeded, the sales consultants and cashiers received a bonus of $50 \%$ of their salary (tariff rate).

The author proposed to divide the basic sales volume of the month into 3 shifts of workers, and take into account the labor contribution not of the entire sales department, but the labor contribution of each work shift. This introduces certain difficulties in fixing financial results, but this is a healthy element of competition in the work of staff.

In the new bonus system, the figure of 200 thousand rubles was taken as the base sales of the month. If this number is exceeded, the working shift of sales assistants is completed, and the cashier receives a premium of $60 \%$ of his salary (tariff rate). That is, the value of the premium for the implementation of sales volume was increased by $10 \%$. But since there are seasonal sales fluctuations at trade enterprises, in certain months it is allowed to reduce the base output to 170 thousand. The data on the output, by the author, is set somewhat higher than the employee's existing capabilities to encourage them to move and develop.

The payment of management personnel was proposed to be built in the same way as the line staff. Table 2 presents the size of the proposed overhead for management personnel.

Table 2. The size of the proposed allowances to the tariff salary of the managerial staff of LLC "FixPrice"

\begin{tabular}{|c|c|c|}
\hline Allowances & $\begin{array}{l}\text { Amount of } \\
\text { Allowance }\end{array}$ & Condition of Allowance Payment \\
\hline \multirow{4}{*}{$\begin{array}{l}\text { 1. Premium for } \\
\text { work experience }\end{array}$} & $20 \%$ of the salary & 2 years of uninterrupted work experience in the "FixPrice" \\
\hline & $30 \%$ of the salary & 3 years of uninterrupted work experience in the "FixPrice" \\
\hline & $40 \%$ of the salary & 4 years of uninterrupted work experience in the "FixPrice" \\
\hline & $50 \%$ of the salary & 5 years of uninterrupted work experience in the "FixPrice" \\
\hline \multirow{3}{*}{$\begin{array}{l}\text { 2. Premium for } \\
\text { management } \\
\text { level }\end{array}$} & $50 \%$ of the salary & level 1 - leader \\
\hline & $40 \%$ of the salary & level 2 - deputy heads \\
\hline & $20 \%$ of the salary & Level 3 - Head of Direction \\
\hline
\end{tabular}

Source: Authors.

The premium for the level of education for management personnel was not introduced, so initially people who have higher professional education are employed

For management personnel, the bonus rate is used - the complexity and intensity of work. Bonus conditions - the excess of the base sales of the month. When base sales are exceeded, management personnel FixPrice receives a bonus of $70 \%$ of their salary. The basic sales volume of the month is set at 500 thousand rubles.

All proposed changes will be valid for a year, after which the results of the effectiveness of the proposed measures will be summarized. Most employees of the sales department immediately noticed the difference between the old and the new staff incentive system.

Stage 5. At this stage, the question of the distribution of benefits among employees was addressed. Along with the employee benefits and guarantees established by the legislation of the Russian Federation, it is necessary to use benefits and compensations that improve the social security of employees, such as:

Benefits related to working time (flexible working hours, the provision of additional days of rest, etc.);

- various additional payments by employees in connection with anniversaries, holidays, vacations, childbirth, etc.;

- organizing preferential or fully paid meals for employees; 
- providing workers with transport or compensation for the cost of travel to work;

- the provision of vouchers to employees and their families in health and recreation facilities; organization of recreation for children of the company's employees; pay for training employees and their children;

- payment of children's institutions to employees of the company; additional non-state provision of employees;

- insurance of employees.

In addition, social benefits include various payments to employees for personal celebrations, say, on the occasion of 10-, 20-, 30-year-olds, etc. anniversaries of official activity at the enterprise in combination with special leave. Moreover, the size of payments and the duration of additional leave may depend on the length of service in the enterprise.

Providing employees with an additional old-age pension also motivates employees. Staff turnover will be reduced, because employees will hold on to their jobs, knowing that after retirement they will receive additional support from the enterprise, which, in turn, will help them maintain their standard of living. Serious motivating role carries in itself the provision of employees the right to use social services. This kind of social services can be divided into four groups: catering staff; provision of housing and benefits for its acquisition; organization of medical care; social advisory assistance.

\section{Conclusion}

The proposed model of social policy in the organization can be called a cafeteria. Its essence lies in the fact that the organization provides employees with a certain basket of social benefits for a certain amount, from which they can independently choose certain social benefits and vary them within the existing budget, that is, make up for themselves the so-called "social menu".

To create high motivation among employees to achieve the company's goals is the main task of all managers, so the managers of Best Price LLC should be familiar with the basic theoretical concepts and practical approaches to motivating and encouraging staff to consciously apply them in their daily activities. At such a seminar it is necessary to consider the following questions:

- classical and modern theories of motivation;

- methods of diagnosis of labor motivation;

- types and forms of labor incentives; principles and methods for the formation of the fixed and variable parts of wages;

- development of a social package, etc.

The main goal of the seminar is to mobilize and set up the management team for active and fruitful work. Without the direct participation of all managers, the improvement of the incentive system will be ineffective.

Thus, the proposed measures will improve the staff incentive system in the sales department "FixPrice", and the proposed external motivation model will not only take into account the permanent part of wages, but also make the employee's income dependent on labor productivity and the final results of the sales department.

And in conclusion, we consider the possible risks that the management of the organization may face in the implementation of the author's recommendations.

Thus, incentive measures were proposed to retain staff in the future. The developed incentive methods will allow you to purposefully spend the funds allocated by the budget, to more clearly determine the items of expenditure on staff incentives. The active combination of material and non-material forms of incentives allows you to vary the size, frequency, variety and targeting of rewards. 
The system of stimulating the work of workers has become personally oriented, so its foundation, above all, laid not only the results of the work of workers, but also their expectations in recognition of merit, etc., which confirms the presence of effective feedback in the organization.

\section{References}

1. H. Aguinis, H. Joo, R.K. Gottfredson, What monetary rewards can and cannot do: How to show employees the money. Business Horizons, 56, 241-249 (2013)

2. N. Commeiras, A. Loubes, A. Bories, Identification of organizational socialization tactics: The case of sales and marketing trainees in higher education. European Management Journal, 31(2),164-178 (2013)

3. Y.K. Kuo, Organizational commitment in an intense competition environment. Industrial Management and Data Systems, 113(1), 39-56 (2013)

4. L.C. Barton, V. Ambrosini, The moderating effect of organizational change cynicism on middle manager strategy commitment. International Journal of Human Resource Management, 24(4), 721-746 (2013)

5. H. Yamamoto, The relationship between employees' perceptions of human resource management and their retention: From the viewpoint of attitudes toward job specialties. International Journal of Human Resource Management, 24(4), 747-767 (2013)

6. Y. Cheng, I.S. Chen, C.J. Chen, H. Burr, H.M. Hasselhorn, The influence of age on the distribution of self-rated health, burnout and their associations with psychosocial work conditions. Journal of Psychosomatic Research, 74(3), 213-220 (2013)

7. D.S. Schultz, V.M. Brabender, More challenges since Wikipedia: The effects of exposure to internet information about the Rorschach on selected comprehensive system variables. Journal of Personality Assessment, 95(2), 149-158 (2013) 